\title{
Feasibility of using of accelerated test methods for determination of frost-resistance for concrete
}

\author{
Anna Pavlenko, ${ }^{1,}$, Anastasia Mishakova ${ }^{1}$, Olga Pertseva $^{1}$, Victoriia Ivanova $^{1 *}$, Yanis \\ Olekhnovich ${ }^{1}$, and Gleb Averchenko ${ }^{1}$ \\ ${ }^{1}$ Peter the Great St. Petersburg Polytechnic University, 195251 St. Petersburg, Russian Federation
}

\begin{abstract}
The article presents the results of studies of innovative materials in the field of testing frost resistance. In fact, present accelerated methods for the determination of concrete frost resistance have high labour consuming and low effectiveness. Moreover there is no such accelerated methods which can be sufficiently applicable fro different innovative concretes, for example, concretes with SAP or self-compacting concrete and so on. Therefore, it is highly important to investigate new accelerated test method with high operability, efficiency and sufficient precision. Previously, two new methods were developed. The main purpose of the research is to compare these methods by evaluation of their technology and accuracy and, consequently, to identify the more sustain and efficient one. First method is based on estimation of energy release due to mechanical fracture and thermo cycling. Second method consists of the calculation value $\mathrm{z}$ (relation between relative decreasing of strength and relative strain in the direction perpendicular to compression) and replacement of thermo cycles by mechanical cycles. Both methods have high operability and do not take a lot of time, in was tested on the 10 specimens made of concrete and results were compared with values derived by standard method.
\end{abstract}

\section{Introduction}

Nowadays different kinds of new additives are more often used by the time of producing of concretes from cement. It means properties or concrete and concrete mixture are influenced of not only such basic parameters as cement type [1], type of aggregates, water-cement ratio but also of amount of additives and their types $[2,3]$. Using od additives improves the desired properties of concrete and concrete mixes [4,5,6], such as workability, durability, water resistance and frost resistance [7,8]. However, the use of new additives, as well as the use of any new technology, requires prior testing. Thus, in order to facilitate the introduction of new technologies in the production of concrete it is necessary to simplify the process of laboratory testing of its properties [9]. For example, it is proved that the direct and indirect methods for determination of the strength of concrete give similar results [10] and using of indirect methods largely simplifies the indication of its basic parameters. However, for the determination of frost resistance of concrete the replacement of direct way by indirect is not sufficient in order to determine the strength, because, according to the basic method all

\footnotetext{
*Corresponding author: pavlenko_ad@spbstu.ru
} 
specimens shall be subjected to repeated freeze-thawing. Therefore, it is necessary to create a new method of accelerated laboratory tests to evaluate frost resistance of various natural and artificial stones and other porous materials, especially innovative types of concretes.

The Worldwide experience offers a vast number of ways for determination of durability of the concrete structures [10], but accordingly to the European standard EN 206:2013 and Swedish Standard 2005 there are four main methods to determine the concrete frost resistance: Slab test, CDF, CIF-Test and Cube-Test. These test methods contain the following steps: curing and preparing the specimens, pre-saturation of the specimens and their thermo cycling. The test liquid simulates a deicing agent which contains $3 \%$ of $\mathrm{NaCl}$ weight and 97\% weight of (demineralized) water in case of the freeze-thaw test and deicing salt resistance and demineralized water to test the freeze-thaw resistance of concrete respectively. Scaling of the specimens is measured after a well defined number of freeze-thaw cycles and leads to an estimate of the resistance of the tested concrete against freeze-thaw damage [11]. The test methods however differ in terms of their procedures and conditions [12]. Also CIF test shows determination of internal damage by measuring the relative dynamic modulus of elasticity (taking into account ultrasonic transit time) [13].

There are two different standard types of methods of determination concrete's frost resistance - basic and rapid in Russian Federation. Basic methods include production and test of samples by series. Further, all samples have been sated by water and part of samples have been alternated repeating freezing and defrosting. After that all samples have been destroyed by compression. For comparison of average values of strength, both types of samples are taken: tested with freezing defrosting, and not. The next step is to define relative decreasing in strength of material under different number of term cycles. Concrete's frost resistance is defined by number of thermo cycles, which necessary for decreasing in strength in limits, stipulated by the standard.

During estimation of concrete's frost resistance considerable random dispersion of values of concrete strength (variation coefficient $\rho=15 \ldots 20 \%$ ) under invariable conditions of production and tests of samples gives rise to a wide scatter of average values of strength and demands large volume test (quantity of test pieces $25 \ldots 50$ ) as proof that relative decreasing in strength of $\Delta \mathrm{R} / \mathrm{R}=0.05 \ldots 0.15$ as a result of freezing defrosting.

Consequently, the basic methods have two main weaknesses: high labour input and small operability. Determination of frost resistance by basic methods takes big time intervals (from 1 to 6 months), so the rapid methods are necessary.

European standards in the field of determination have some differences but they still have no enough operability and high labor input $[14,15]$.

Except basic methods accelerated methods which considerably simplify the determination of frost resistance but still have another serious disadvantages [16]. For instance, dilatometric method [17] which is a prototype for methods described below is acceptable only for concretes based on portland cement and blastfurnace cement without any SAP and other additives. Method with using of flatbed scanner is also restricted in application [18].

Therefore, it is highly important to create new method which will be much more efficient, especially for innovative concretes with SAP, various additives and extra properties.

\section{Energy released method}

The First method which is based on energy release includes the following key steps:

- measurement of the relative tension set of a specimen $\theta_{t e n}$ after the one cycle of freezing defrosting by dilatometer (here the DOD-100-K dilatometer has been used);

- $\quad$ measurement of the greatest nondestructive loading $L_{0}$ of a specimen in the conditions of stretching by acoustic methods for the nondestructive testing of concrete [11] (here AF-15 
AE-complex by Kishenevskiy has been used) to determinate specimen's long-time strength $R_{l t}$ in the conditions of stretching;

- measurement of the short-term strength R.

In time of freezing, development of concrete's damages is explained by subcritical cracks growth. In brittle solids cracks begin taking off by a shearing action [19], also the speed of their development is no more than $10-4 \mathrm{~m} / \mathrm{s}$. Therefore in conditions of freezing water, the filled crack in concrete captures the nearby closed pores. It stabilizes pressure in the water of the filled crack by about the value causing stretching tension in a material equal to long-time strength of a specimen in the conditions of stretching [20]. If the body's temperature changes from $78 \mathrm{~K}$ to $1493 \mathrm{~K}$ and the loading is as described earlier, the $L_{0}$ value shifts inside of deviation determination of it, i.e. $1 \div 3 \%$. This fact permits using the $L_{0}$ value received at low temperature when the energy per unit of the specimen's volume which is disseminated in the course of freezing-defrosting is established.

If $L_{0}$ is determined, it is possible to calculate a specimen's long-time strength $\mathrm{R}_{\mathrm{lt}}$ in conditions of stretching:

$$
R_{l t}=2 L_{0} / \pi S
$$

where $S$ is an area of a specimen's section perpendicular to compression planes, $L_{0}$ is the greatest non-destructive loading of a specimen in the conditions of stretching.

Definition of a relative tension set and long-time strength of a specimen allows estimating the energy disseminated on processes destructions in the course of freezing-defrosting $W_{t c}$ as per formula:

$$
[W]_{t c}=\theta_{t e n} R_{l t}
$$

where $\theta_{\text {ten }}$ is the relative tension strain of a specimen, $R_{l t}$ is a specimen's long-time strength in the conditions of stretching.

Specimen's loading in the conditions of monoaxial compression to extreme loads, registration of these values of axial loads and axial strain is corresponding to loads, which allows calculating energy per unit of the specimen's volume which is disseminated in the course of its compression to extreme loads by numerical integration of dependence of axial loading from axial strain. Value of the energy disseminated in the unit of volume of a specimen in the course of its compression to extreme loads is in proportion to a square value of short-term strength:

$$
W_{\text {com }}=\alpha R^{2},
$$

where $R$ is a short-term strength, $\alpha$ is a proportionality coefficient.

The logarithmation and differentiation of expression (7) allows the calculating of specimen's freeze-thaw resistance $F_{\text {sam }}$ as per formula:

$$
F_{\text {sam }}=2[\Delta R / R] \cdot W_{c o m} / W_{t c},
$$

where $[\Delta R / R]$ is a standard relative decreasing in terms of strength $([\Delta R / R]=0.05 \ldots$ $0.15)$.

Concrete's freeze-thaw resistance is found as an average of freeze-thaw resistance values for specimens.

\section{Method based on strains ratio}

The second offered way is realized as follows: 
- Measurement after each thermocycle relative tension strain $\varepsilon_{T i j}$ for every specimen from the set (in this method the set is from 5 to 10 specimens).

- After thermocycling each specimen is loaded in the conditions of monoaxial compression in the regime from Fig. 1 in order to indicate extreme (maximum) value of loading of the first loading $L_{\max }=L_{1}$ of and extreme loading of the second loading $L_{2}$.

- $\quad$ After finishing first unloading without shift of a specimen measure tension strain of $i$ that specimen in the direction, perpendicular to compression is measured.

Relative tension strain $\varepsilon_{0 i}$ in the direction, perpendicular to compression, for $i$-that specimen is counted as per formula:

$$
\varepsilon_{0 i}=\frac{\Delta a_{i}}{a_{0}},
$$

where $a_{0}$ is the size of $i$-that specimen before compression in the direction, perpendicular to compression; $\Delta a_{i}$ is a relative change of this size.

For $i$-that specimen relation of $z_{i}$ of relative decreasing in strength to relative tension set in the direction, perpendicular to compression is counted as per formula:

$$
z_{i}=\frac{\left(L_{1 i}-L_{2 i}\right)}{L_{1 i} \varepsilon_{O i}}
$$

where $L_{1 i}$ and $L_{2 i}$ - extreme loading of i-that specimen at the first and second loading respectively, $\varepsilon_{O i}$ - relative strain in the direction, perpendicular to compression for $i$-that specimen.

Then value of the relative strain $\varepsilon_{m}$, corresponding to relative decrease in strength allowed by the standard, for $i$-that specimen is counted as per formula:

$$
\varepsilon_{m i}=\frac{\lfloor\Delta R / R\rfloor}{z_{i}},
$$

where $[\Delta R / R]$ is a relative decreasing in strength allowed by the standard. 


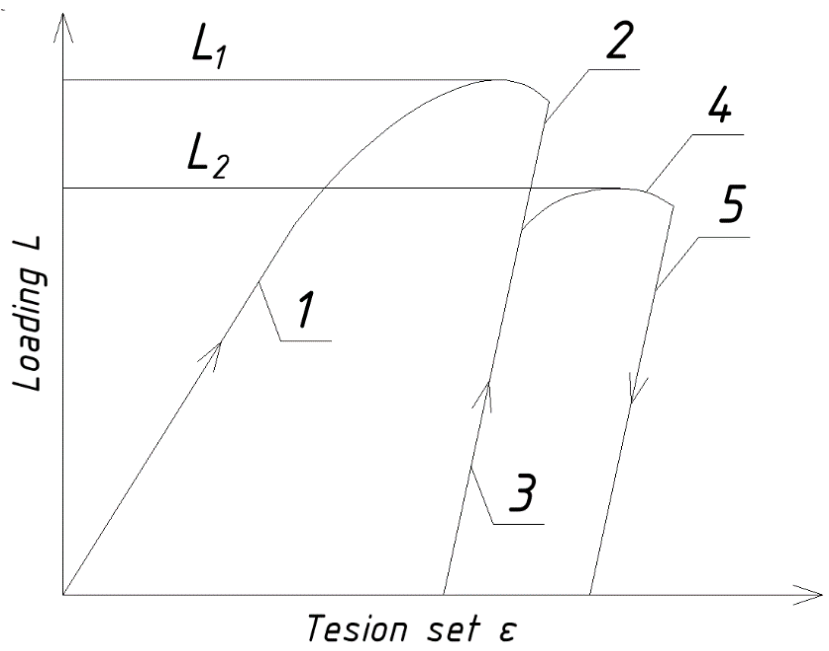

Fig. 1. Shedule of specimen loading in conditions of monoaxial compression after thermocycles: 1 line of first loading; 2 - line of first unloading; 3 - line of second loadind; 4 - line of second loading; 5 - line of second unloading; $\varepsilon$ - relative longitudinal tension set; $L_{l}$ - extreme loading of the first loading; $L_{2}$ - extreme loading of the second loading.

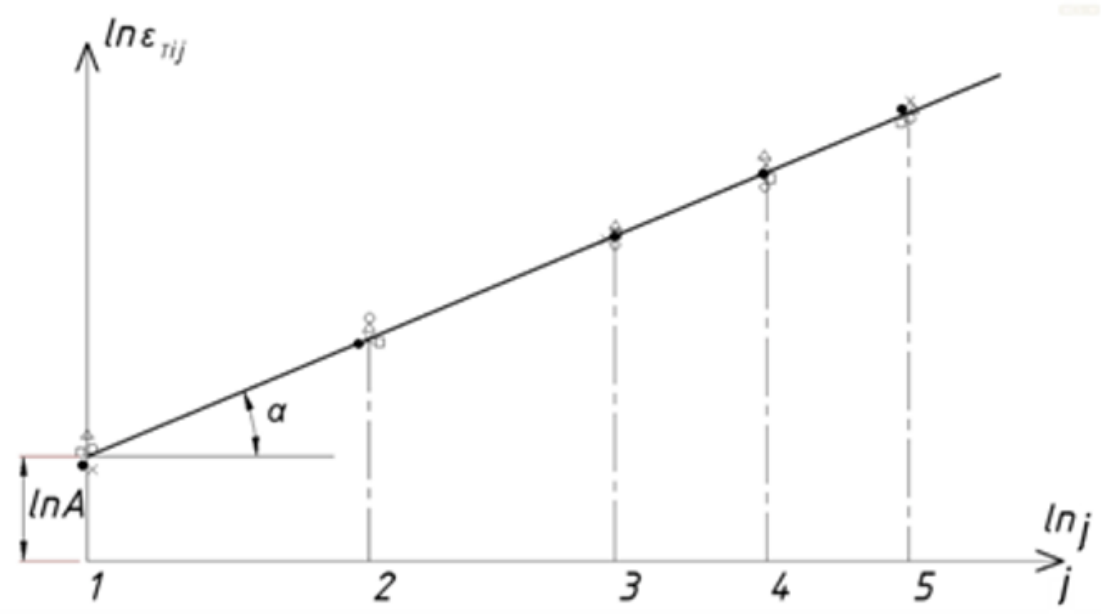

Fig. 2. Shedule for determination of parameteres $A$ and $\lambda$ from dependence $\varepsilon T=A j^{\lambda}$ by data about $\varepsilon T i j$ for $i$-specimen after $j$-thermocycle: $j$ - number of thermocycle; $A$ - temperature relative tension set after the first thermocycle; $\alpha-$ a straight line tilt angle to a horizontal; $\odot, \square, \Delta, \cdot, \times-$ the points received by results of tests, respectively, I, II, III, IV and the V specimens.

According to the correlations $\varepsilon_{T}=A j^{\lambda}$ and $\varepsilon_{m j}=A F_{j}^{\lambda}$, where $A$ is a strain after first cycle (freezing-thawing or loading-unloading) frost resistance can be derived from next equation:

$$
\frac{\varepsilon_{m j}}{\varepsilon_{T i j}}=\left(\frac{F_{i}}{j}\right)^{\lambda} \Rightarrow F_{i}=j\left(\frac{\varepsilon_{m i}}{\varepsilon_{T i j}}\right)^{\frac{1}{\lambda}}
$$


where $F_{i}$ is a frost resistance of $i$-that specimen, $\varepsilon_{T i j}$ is a relative strain of $i$-that specimen after the $j$ thermocycle, $\varepsilon_{m i}$ is a relative strain after compression, $j$ is a number of thermocycles.

Frost resistance of a material should be determined as an average from $F_{i}$ for all specimens.

\section{Methods realization}

Both methods were performed on 10 specimens (cubes with side of $10 \mathrm{~cm}$ ) for every method. In addition, 100 specimens were tested by basic method. Concrete was prepared from following mixture: Brand 400-1 Portland cement weight part, sand - 2 weight parts, granite rubble $5 \ldots 20 \mathrm{~mm}-4.5$ weight parts, waters -0.6 weight parts and in was hardened for 88 days. Received frost resistance of such concrete by basic method were derived as 105 cycles. Before testing all specimens were saturated by water according national standards. Results for method based on energy released are provided in Table 1 and results for method based on strains ratio are provided in Table 2.

Table 1. Results by method based on energy release.

\begin{tabular}{|c|c|c|c|c|c|c|}
\hline № & $\begin{array}{c}\bar{R}_{l t}, \\
\mathrm{MPa}\end{array}$ & $\theta_{\text {ten }} \cdot 10^{4}$ & $\begin{array}{c}W_{t c} \cdot 10^{4}, \\
\mathrm{MPa}\end{array}$ & $\begin{array}{c}W_{\text {com }} \cdot 10^{4}, \\
\mathrm{MPa}\end{array}$ & $\begin{array}{c}{[\Delta W] \cdot 10^{2},} \\
\mathrm{MPa}\end{array}$ & $F_{i}$ \\
\hline 1 & 1.5 & 2.7 & 4.05 & 0.9990 & 2.997 & 74 \\
\hline 2 & 1.7 & 3.1 & 5.27 & 1.7215 & 5.165 & 98 \\
\hline 3 & 1.8 & 1.8 & 3.24 & 1.2312 & 3.694 & 114 \\
\hline 4 & 1.9 & 2.6 & 4.90 & 1.6796 & 5.039 & 102 \\
\hline 5 & 2.0 & 2.5 & 5.00 & 1.4333 & 4.300 & 86 \\
\hline 6 & 2.1 & 1.9 & 4.00 & 1.4364 & 4.309 & 108 \\
\hline 7 & 2.2 & 2.6 & 5.72 & 2.2308 & 6.692 & 117 \\
\hline 8 & 2.3 & 2.1 & 4.83 & 1.3846 & 4.154 & 86 \\
\hline 9 & 2.9 & 1.8 & 5.22 & 1.6008 & 4.802 & 92 \\
\hline 10 & 3.1 & 1.5 & 4.65 & 1.8600 & 0.558 & 120 \\
\hline Average & 2.15 & 2.1 & 4.69 & 1.5577 & & 99.7 \\
\hline
\end{tabular}

Table 2. Results by method based on strains ratio.

\begin{tabular}{|c|c|c|c|c|c|c|}
\hline № & $\Delta R / R$ & $\varepsilon_{0 i} \cdot 10^{3}$ & $z_{i}$ & $\varepsilon_{T i 5} \cdot 10^{5}$ & $\varepsilon_{m i} / \varepsilon_{T i 5}$ & $F_{i}$ \\
\hline 1 & 0.093 & 8.86 & 10.50 & 56 & 24.78 & 76 \\
\hline 2 & 0.077 & 6.99 & 11.02 & 42 & 33.04 & 97 \\
\hline 3 & 0.105 & 9.91 & 10.60 & 40 & 34.69 & 102 \\
\hline 4 & 0.081 & 7.49 & 10.82 & 38 & 36.5 & 106 \\
\hline 5 & 0.092 & 7.95 & 11.57 & 38 & 36.5 & 106 \\
\hline 6 & 0.063 & 5.83 & 10.80 & 37 & 37.5 & 109 \\
\hline 7 & 0.114 & 10.16 & 11.22 & 36 & 38.54 & 111 \\
\hline 8 & 0.080 & 7.66 & 10.40 & 34 & 40.81 & 117 \\
\hline 9 & 0.106 & 9.53 & 11.12 & 33 & 42.05 & 120 \\
\hline 10 & 0.096 & 9.55 & 10.05 & 31 & 44.76 & 127 \\
\hline Average & 0.92 & 8.40 & 10.81 & & & 107 \\
\hline
\end{tabular}




\section{Results}

Both methods have high operability and small labor input. Because of small number of specimens which should be tested it does not take a lot of time. Moreover, both methods provide results with high accuracy, but method based on strains ratio are more accurate. Divergence of method based on energy release with basic method is 5,3\% whereas divergence of method based on strains ratio is $1.9 \%$. Therefore, method based on strains ratio are more accurate and better matched for determination of concrete frost resistance.

\section{References}

1. G. Skripkiunas, D. Nagrockiene, G. Girskas, et al., Procedia Engineering, 257, 10451051 (2013) DOI: 10.1016/j.proeng.2013.04.132

2. L. Akimov, N. Ilenko, R. Mizharev, et al., Applied Mechanics and Materials, 725-726, 461-468 (2015) DOI: 10.4028 / www. scientific. net / AMM. 725-726. 461

3. A. Kharitonov, M. Korobkova, O. Smirnova, Procedia Engineering, 7, 239-244 (2015) DOI: $10.1016 /$ proeng.2015.06.143

4. Y. Barabanshchikov, M. Komarinskiy, Applied Mechanics and Materials, 725-726, 419424 (2015) DOI: 10.4028 / www. scientific. net / AMM. 725-726. 419

5. Y. Barabanshchikov, A. Arkharova, M. Ternovskii, Magazine of Civil Engineering, 51 (7), 23-30 (2014) DOI: 10.5862/MCE.51.3

6. A. Frolov, A. Cherkashin, L. Akimov, et al., Applied Mechanics and Materials, 725-726, 425-430 (2015) DOI: 10.4028/www.scientific.net/AMM.725-726.425

7. D. Nagrockien, G. Girskas, G. Skripkiunas, Construction and Building Materials, 66, 45-52 (2014) DOI: 10.1016 / j. conbuildmat.2014.05.025/

8. S. Nikolskiy, O. Pertseva, IOP Conference Series: Materials Science and Engineering, 123 (2016) DOI: 10.1088/1757-899X/123/1/012047

9. M.A. Kewalramani, R. Gupta, Automation in Construction, 15, No. 3, 374-379 (2006) DOI: 10.4028 / www. scientific. net/KEM. 689. 108

10. A. Köliö, T. Rantala, et al., 5th International Conference on Concrete Repair: Concrete Solutions - Proceedings of Concrete Solutions, 533-539 (2014) DOI: 10.1201/b1739483

11. M. Lelusz, D. Malaszkiewicz, Journal of Civil Engineering and Management, 10(1), 3136 (2004) DOI: 10.1080/13923730.2004.9636283

12. J. Shanshan, Z. Jinxi, H.Baoshan, Construction and Building Materials, 47, 126-130 (2013) DOI: $10.1016 /$ j. conbuildmat.2013.04.040

13. G. Nesvetaev, Y. Koryanova, T. Zhilnikova, MATEC Web of Conferences, 196, No. 0401 (2018) DOI: 10.1051 / matecconf / 201819604018

14. M. Radlinski, J. Oleic, et al., Journal of ASTM International, 7, No. 4 (2010) DOI: $10.1520 / \mathrm{JAI} 102453$

15. Concrete. Specification, performance, production and conformity, 206, BS EN (2013)

16. A. Khodakov, M. Tochenyy, et al., Applied Mechanics and Materials, 633-634, $997-$ 1001 (2014) DOI: 10.4028/www.scientific.net/AMM.633-634.997

17. RILEM Technical Committee, TDC, CDF Test, Method for the Freeze-Thaw-Resistance of concrete with sodium chloride solution, RILEM TC 117-FDC, 27, Recommendation, Germany (2001) 
18. Concrete testing - Hardened Concrete-Frost Resistance, SS 137244 (Swedish Standard, Sweden, 2005)

19. A. Gokce, C. Nagataki, et al., Construction and building material, 25(5), 2426-2431 (2011) DOI: $10.1016 /$ j. conbuildmat.2010.11.054

20. D. Serdjuks, K. Rocens, L. Pakrastinsh, Baltic Journal of Road and Bridge Engineering, 3, 129-136 (2008) DOI: 10.3846/1822-427X.2008.3.129-136 